\title{
A CASE STUDY: WHAT ARE THE PRACTICES LIBRARIANS USE IN IMPLEMENTING AND DETERMINING STORING KNOWLEDGE INTO DIGITAL DATA WAREHOUSES AND ARCHIVES
}

\author{
Scott C. Spangler, California University of Pennsylvania, spangler@calu.edu \\ Paul J. Kovacs, Robert Morris University, kovacs@rmu.edu \\ Lisa Kovalchick, California University of Pennsylvania, kovalchick@calu.edu
}

\begin{abstract}
In today's globalized information age, data-warehousing decisions for library science deans and librarians are complex. The purpose of this research is to understand and discover the key principle or core decisions librarians in higher education situations make in determining what data should be warehoused in the digital information age.
\end{abstract}

Keywords: digital archiving, preservation, digital preservation, university library digital archives, preserving knowledge

\section{INTRODUCTION}

In universities, knowledge can mean a competitive advantage. Technologies today have changed the way we think, act, and interpret information. The digital media tidal wave has swept all aspects of industry, knowledge archiving and storage, even in our minds. These technologies have "shaped and reshaped the circuitry in our heads" and changed the way we use tools [1]. Scholars such as Carr [1] contend we are losing the ability to have a "cognitive load" or ability to memorize and store knowledge. The human mind is becoming "shallow" and attention deficit disorders are increasing, so the digital technologies and Net are becoming an informational medium [1]. Memories are becoming "artificial" in the "magical information age" [1]. Students today have the attention span of a "gnat" and are "no longer the people our educational system was designed to teach" [2].

Cyberspace brought to us through our computers is non-descript bits of code and data that are seen as a "web of information" by digital natives and digital immigrants [3]. Our ideas and understandings in society today are "reductive understandings" and we are a society that "trusts what we see, and analyze completely" from our empowered cyber technologies [3]. Disruptive technologies improve and shift competitive focuses in all markets including higher education and library science practices. Traditional learning institutions and styles are forgone to disruptive technologies in education and "universities are an anomaly" that can't escape sustaining innovations and technologies [4]. Innovations today, 2014, should be seen by universities as a "strategy for success" to unrestricted knowledge and learning by students and faculty for boarder scholarship [4].

Digital archiving in libraries and archives has a long-term, low-cost alternative to traditional warehousing of printed data. The digital archiving process offers an alternative to microfilming archives at a lower cost and higher resolution that suffers low-loss rates and "enhances access to library material" [5]. With digital archiving, neglected scholarly materials, often caused by damp storage and human abuse, considered "sufficiently unsalable not to be worth the cost of warehousing them" do not have to face the eternal grave in a university "dumpster" [5].

The purpose of this research is to understand and discover the key principle or core decisions librarians in the Pennsylvania State System of Higher Education make in determining what data should be warehoused in the digital information age. The study is designed to create, implement a methodology, and design further research in library archiving systems. Specifically, the study was conducted to answer the following research questions:

RQ1: What knowledge or research do librarians find paramount to digitally archiving information for the future?

RQ2: Do librarians find that certain types of knowledge bases are more important than others? 
RQ3: What key factors would librarians place on an archival hierarchy scale?

\section{DEFINITION OF TERMS AND LITERATURE REVIEW}

Data is a collection of "numbers, measurements, and simple signs" used to organize "structures" to create information [6]. Information is a series of "patterns" formed from data to "qualify as knowledge" [6]. Knowledge comes in two forms: tacit or explicit. Tacit knowledge is found in our minds and "doesn't classify as knowledge [7]. Although, Polanyi [8] said, "all knowledge is fundamentally tacit." Once tacit knowledge is "written" or "posted" it becomes explicit [8].

Knowledge is what "exists in peoples' heads" and through speech or other means. Knowledge is shaped from active experiences [9]. Knowledge experiences are formed organically in social interactions that form "consciousness, or ideas, and impressions" [10]. Knowledge creates "information" [11]. Knowledge management is a "conscious strategy" or method of "helping people share" information for improvement or "performance" [7]. Knowledge is generated through people in fluid "framed experiences, values, contextual information, and expert insight that provides a framework for evaluating and incorporating new experiences and information" [12].

\section{Information Sharing and Transfer}

Information sharing or "moving" from "sender to recipient" creates communication [6]. Communication is the process we utilize to send "voice, written message, or gesture" that becomes "observable, measurable and recordable" [6]. Communication effectiveness relies on the "transmitter and receivers" ability to "decode" information without "interference" or "noise" over a channel [6]. The transmitter "sends the "signal" [6]. The receiver "decodes the message and gives it to the destination" [6]. The "bits" (information) accuracy relies on the system's ability to filter out "noise" [6]. A system is "anything that has organization of parts that are put together to achieve a purpose" or value [6].

A value proposition is "created by translating knowledge into action" [7]. Computers

Assist in the transmission of the characteristics (data) of the events occurring in time and space, expand our awareness of the world about us, and aid in our understanding of these events, enabling us to respond to them [6].

Personal computers or private computer systems "built and operated by individuals companies" use the "intranet" to transmit information worldwide through a "common grid" [13]. Networks of computers link "databases of billions of Web pages... match up with keywords, arrange them in order of relevance, and shoot back results" in order of "relevance" [13].

\section{Novel Technologies}

Novel technologies or "inventions" use new "principles" or "concepts," which "arise from linking, conceptually and physically in form," to fulfill a need or "exploitable effect" [14]. Data warehousing is a principal allocation, whose goal is to "conserve" valued data to ensure that information reaches its potential [15]. Information is data "endowed" with relevance and purpose [16]. The roles of a data archive include the "acquisition, preservation, and documentation, processing, cataloguing, disseminating and supporting use of data. Formats preserved vary according to the type of data" [15].

Digital archiving roots trace back to the 1960's in Europe. International Social Science Council (ISSC) created a Committee on Social Science Data Archives [15]. The goal of the international collaborative initiative was to construct an archive to provide "cooperation in the collection, processing, storage, retrieval, exchange, and use of machine-readable social science data" [17]. The fluid system of knowledge derives from the scholars, and would be used to centralize knowledge into one digital data archive. 
Archiving digital data "requires that data are [sic] preserved in formats that can be accessed by researchers, now and in the future" [15]. Scholars contend "digital artifacts are intentionally incomplete and perpetually in the making" [18]. This fluid process is considers digital artifacts "stable," but in a method of being theorized [18].

\section{Digital Preservation}

Digital material is "information resources that have been-created in digital form, i.e. their life begins in digital form (i.e. Born digital resources), and those that have been converted from print or paper-based resources (i.e. analog) to digital formats (i.e. Made digital or Digitized resources);" [19]. Digital artifacts or knowledge data sets are "pliable" in principle, and have the capability "modify or update continuously and systematically." The digital artifacts can assume many forms from PDFs, Blog sites, Internet sites, and even bits of information that "assumes various forms." The forms can be created by "rearranging the elements of which a digital object is composed (such as items in a digital list or subroutines in a software library), by deleting existing or adding new elements, or even by modifying some of the functions of individual elements" [18].

Data storage of knowledge or digital material started on analog tapes and then eventually spinning disks before leading to the collation created by the MetaArchive Cooperative. Digital medias no longer have stored backups in analog or paper form, which created a need for understanding about how to preserve the "born digital" knowledge [19]. The Library of Congress' National Digital Information Infrastructure and Preservation Program (NDIIPP), and the International Organization for Standardization's Open Archive Information Systems gave way to a federal collaboration system in the same time span. This gave libraries a "sense of security" but also a fear of "obsolescence," where information archived today, 2014, may not be supported in platforms six-months from now because of the speed of innovation in technology [20].

The National Digital Stewardship Alliance states its mission as being to "maintain, and advance the capacity to preserve our nation's digital resources for the benefit of present and future generations" with five digital stewardship areas: Content, Standards and Practices, Infrastructure, Innovation, and Outreach. The concept of preservation means to "store" and have archival methodologies in place for retrieval of knowledge in the future of historical data [19].

The NDSA's Standards and Practices group surveyed 85 institutions about best practices and preservation methodologies. In their 2012 paper, the group found that only $33 \%$ of the respondents have a dedicated digital preservation team, and $57 \%$ of the respondents thought it was "extremely important for anyone being hired to generate and store digital archives have a working knowledge of digital preservations standards" [21]. The fundamental practices the Standardization and Preservation group focuses on are encoding, describing, preserving, and transference of digital artifacts.

The NDSA's Working Content group has recently started a series of case studies on understanding practices in nongovernmental spheres. The NDSA's case study reflected no working understanding of the spheres activities. It does, however, point out the need to understand public journalism or public citizens' activities in preservation efforts. The case study points out the need for capitalizing on and preserving public citizens' artifacts and captured innovations archives (information received through today's, cell phone technologies). The group points out, however, who the key stakeholders should be in the project: local communities, historical societies, newspaper publishers, genealogical societies, and local high schools [22]. This need for an archiving structure and presence is necessary in the public domain. With the onset and public understanding of digital decay theory, best practices for preservation are necessary for individuals. Overall, today, the average individual does not understand the speed or connection to digital decay of archives.

Almond [23] states:

"Digital decay is something that's happening every day of our lives, we are often simply unaware of it until it's too late. But there is a growing movement of people embracing it, encouraging it and using it to make art, to make money and to explore the possibilities of all this digital equipment that we now run our lives with."

Currently, libraries are archiving knowledge, but in the process they are creating a new and larger set of 
discriminatory problems. First, libraries' knowledge archiving practices are individual and not normalized across the systems of public and university libraries. On-line resources are being cataloged, but there are "no stable identifiers or achievable content" which would unify and normalize the inter-library communications systems [20]. Secondly, decay is readily happening, as there is no monitoring of digital links and retrieval tools. Third, digital corruptions in the metadata or in the bytes "could mean loss in the whole digital archive" [20].

NDSA's [24] case study pointed out key stakeholders that are paramount to generating and cataloging digital knowledge preservation. One stakeholder, a journalism school, is considered a key informant area to institute best practices, policies and ideas about knowledge archiving and preservation, and to help develop community "ties" [24]. In the ties, the NDSA's [24] case study cited newspapers changes as a major issue or case to focus on as a stakeholder in knowledge. Newspapers today are no longer microfilming assets, but relying on utilizing PDF documents as stored archives. These archives, which area key to historical happenings and active reports in communities, are "not readily maintained" by publishers. The NDSA recognizes the notion that publishers in the journalism industry have not had a positive relationship with public libraries towards storing these artifacts, which readily causes eminent decay of digital knowledge [24]. The NDSA's case study failed to consider a key factor in archiving and digital preservation- costs.

Anbu \& Chibambo [19] describe the costs associated with preservation:

"Cost implications depend mainly on the socio-economic dimension of the information along with the storage, hardware and software cost; and cost over the human resources. The ability to employ and develop appropriate skills in digital preservation entails training and retraining of information professionals as the technology changes."

There are benefits to digital archiving. Accessibility is a great benefit, but at the same time it can suffer larger amounts of "vulnerability." The knowledge or stored data can be more "comprehensive" and require "minimal building-space requirements" but be at the peril of innovation changes that are readily available and changing [25]. Again, these storage skills and innovations in technology are a constant stream of cost implications. Costs associated with the information technologies include hardware, services, internal storage and of "software expenses," which can be provided by a "third party organization" [26]. On the other hand, the digital gap can be reduced or restricted by governments through funding and generating dedicated digital storage space.

Governments can provide "Internet access and search engines free-of-charge to their populace and restrictions can be made an integral part of this access, such that a blacklist of words or phrases are not recognized" [25]. The current library systems need a normalized structure for coding and storing knowledge and data, and preserving archives. The ongoing efforts to collaborate are needed to generate a universal storage and system of public knowledge's through universities to protect data [15]. This generates the need for a normalized universal global initiative for a global information society that focuses on uniting all governments, universities, and community's knowledge [27]. "The dangers of losing vital information rise not only with every technological evolution, but also with political changes. Digitalizing [sic] information does not imply per se the preservation of knowledge" [27]. A need for data migration policies exists to ensure "transfer of digital" knowledge and "configuration" of knowledge in the future [28]. This includes a risk management assessment of information and positive need for greater universal collaboration [29]. Prior analog stores of knowledge or data have been always at the peril of Mother Nature, and so, too, is digital data. This notion must be considered into the cost-vulnerability aspect to preserve knowledge once a normalized system is generated. Institutions must consider all digital artifacts. Artifacts are "qua objects [that] lack the inherent bounds and durability granted by physical underpinnings and traditional media" [18]. Carraway [25] said:

"Fires, floods and earthquakes that damage or destroy buildings housing irreplaceable archives or data farms can happen. Solar flares (coronal mass ejections) have in the past and will at some point in the future disrupt or destroy anything operating on the electrical grid on planet Earth. Although these events happen infrequently, and some may not happen within our lifetime, eventually they all will happen." 


\section{METHODS AND PROCEDURES}

This research followed Asmussen and Creswell 's [30] narrative case study thematic model to determine key factors associated with librarian's regards to knowledge archiving in data warehouses. The model first looked for variables associated in their decision making process, and then coded the variables into themes. The themes were pulled directly from edited quotes from informants. The researchers' brackets themselves into the study by reflecting their interpretation are subjective. Additionally, the researchers disclosed they had no prior knowledge of the process, and later asked the participants for feedback. The feedback was then incorporated into the final study as part of an inmember checking process.

This in-member checking of the data, and constructed themes aided the researchers in constructing missing themes. The themes created an overall understanding or matrix hierarchy into the reasoning why one piece of information (knowledge) over another piece of knowledge may or may not be archived. This qualitative methodology, which is widely used in the grounded theory and ethnographic scholarly fields, spirals the accumulated data into refined variables that are intertwined and linked throughout the entire culture. The methodology encases methods outlined in the theory of practice by James P. Spradley's Participant Observation steps of making a domain analysis from patterns. The methodology creates a consistent, systematic, and categorical method to determining relationships, relationships to whole, and patterns. This methodology is the antecedent and prescribed qualitative methods Asmussen and Creswell 's [30] narrative case study thematic model utilizes in greater analysis depth.

\section{Research Participants}

Ten voluntary participants of Manderino Library staff members and one Dean were interviewed during the week of February 10, 2014. Six males and four females comprised this group. Only two of the participants said that they have little to no experience in archiving digital data or knowledge. All of participants stated they currently use computers to do their research. The participants remarked commonly that they often rely "heavily" on computers to receive news and current events. Only two male participants stated they preferred using E-books or digital books for research and reading, while the majority of the respondents stated that they have tried digital books, but still prefer analog hard copies. Only one stressed a devotion to digital methodologies and readily parted from any form of analog reading.

All of the participants stated that they have seen "over confidence" in patrons' knowledge about how to gain access to digital knowledge. Each participant explained different situations where the "myth" of digital natives and digital immigrant's gap is being deconstructed. Each participant expressed varied stories about digital natives not being able to find information and lacking an overall knowledge base about personal productivity software. In addition, the participants agreed there is an importance to protecting current knowledge and safe guarding peer-reviewed literature for the future. Participants stressed a strong concern about creating a deeper university need for training in the methodology to recover any form of digital knowledge.

\section{Research Validity and Protection}

Through the case study of participant interviews, coded notations were established to ensure participant responses remained anonymous. All participants were assigned a numeric code. Participants' numeric identifiers were only seen in the field note notations and final research. Any active participant source was only identified after verbal and written permission had been granted. Sources granting identification were disclosed only after a signed release form was ascertained.

The interview process was completely voluntary and at any time the participant could choose to stop the interview process, and not be involved in the research. The current Dean, and all participants underwent the short voluntary participant interviews only after the consent to interview form had been completed that explained the interview is voluntary, and their participation can be stopped at any time and for any reason without penalty and all data would be discarded. All of the collected data is confidential, and the participants' remarks will be anonymous. 


\section{RESULTS}

\section{Common Factors and Concerns about Digitalization of Knowledge}

The participants had six common factors of concern about digitalization of knowledge and library resources. These six common factors are:

1. Copyrights on library artifacts and special collection materials

2. Time creating digitalization and storage of knowledge

3. Digital migration and loss of information

4. No backup plan

5. Identifying ownership and, or legal issues

6. Budgetary restraints

The most common thread in the participants concern was they are "held hostage" by publishers that may or may not still own copyrights on library artifacts and special collection materials. Thus, copyright concerns became the first key factor in determining ability and merits for digitalization and storage of knowledge. Participants all agreed that "time" was of the second greatest concern about creating a knowledge database. The participants' main concern with allocating time to the project is if the project adventure itself would influence the library's budgetary allocations. The money or budget allocation changes that would be needed to foster a digitalization or knowledge data program are considered an expenditure, which would take away from other purchasing needs. All of the participants were concerned with maintaining "current subscriptions" to online databases. They had a unified fear that budgetary changes or allocations for creating a digitalization of university histories would cut short their abilities to buy into the needed current warehouses of knowledge.

The third key factor participants agreed upon was the fear of digital migration and loss of information. A major concern was the speed of migration in digital knowledge. The participants feared that as fast as they could manage to digitalize knowledge collections, the storage medium would change causing a loss of the established archives. One participant remarked, "A book can last 400 years as long as it's published on acid-free paper, but who today can read an 8-inch floppy disk?" This thought of "no backup" plan was the fourth key factor in the digitalization of knowledge, that the participants recited. The participants shared a concern that money would be a factor in their ability to backup and safe guard any knowledge they would archive. They shared common concerns about loss from digital storages being corrupted or destroyed in a possible "flood," "fire," or some sort of "power serge" or loss.

The fifth key factor the participants agreed upon was "permission." The participants all consider "permission" or legal issues a problem. The participants considered the donated special collections and university property as a frontrunner in their developing a plan to protecting current stored information. The collection, which has already established permissions, would be the participant's first suggested pieces of knowledge to protect. A unified concern was the legal aspects about ownership and permission of the housed and stored knowledge in the library. Digitalizing of knowledge that is housed on the university property must have written rights and permissions from the original granter or property owner established before the librarians can copy the analog information. Some of the analog material is lacking in clear identification or ownership. This lack in established university ownership is a unified concern of the participants. The permission issue led to the sixth and final key factor. The participants all reflected an interest and need to store university "faculty research." This added to the concern about permissions overall. The participants expressed concerns about copyrights being given away by faculty members to publishers in order for them to meet university publishing requirements. In addition, current faculty and older retired faculty have not stayed current with updating the library with their personal research.

\section{Adoption of an Archiving Knowledge Hierarchy Processes}

Library staff members pointed to five-key elements to consider as part of a hierarchy scale of importance for protecting and archiving. These five key elements are:

1. University history

2. University's special collections 
3. Yearbooks and collected student run newspaper editions

4. Student thesis knowledge

5. Faculty publications

Participants considered university history as the most important aspect to consider for digitalization. This history included photographs, past presidential speeches, and historical documents. Most of the participants considered the University's special collections a key factor in this allocation, but should and could be considered the second keycontributing factor. Participants pointed out aspects of the special collections such as donated artifacts of local history to be considered the most important in the domain. Three common artifacts re-occurred during the investigations: riverboat building and construction history documentations, the Wilkins' collection, and Brier Hill coal mining records of the county.

Yearbooks and collected student run newspaper editions of history were seen as the third key element. Participants all gravitated around the importance of generating a knowledge warehouse of the yearbooks. Participants had a united concern for archiving the books because of limited quantities in print; many of the catalogs where not printed on acid free paper. There was a unified stress of imperative need for generating digital copies of the student-run newspaper (Cal Times). The newsprint was offset on poor or low quality paper, which is now seeing deterioration and yellowing.

The final set of key factors points towards a need to archive past thesis knowledge generated at the University. Participants agreed about the importance of archiving students' thesis and faculty's thesis or research. They concluded that it was important to save past thesis and future thesis created at the University. This knowledge, unless cataloged by the University, is lost to publisher's rights, or conference committees. Participants stated a majority of faculty papers, and syllabi have never been archived, and currently collected papers need to be protected and searchable.

\section{CONCLUSIONS}

Participants saw the need to create a universal searchable-knowledge warehouse of university history, special collections, and local history that includes faculty research. The key factor, expressed by the participants, was an immediate need to launch a campaign to gain access to current faculty research and past research. In addition, the key factors generated a unified need to consider a budgetary decision tree into launching a digital knowledge warehouse. The participants formulated a great fear of technology migration issues with starting a digital warehouse of achievable knowledge. Two of the participants, who have started their own digital warehouse of important history and knowledge, also stressed the importance of digital migration, costs and time.

Key factors led to a hierarchy scale of importance for items to catalog in the University. Inside each of the key factors remained lesser, but yet still important elements, such as the Marsha Nolf collection (an emerita faculty member's private collection of papers and book donations at the university), anything not generated on acid-free paper, and a donated collection of World War I letters and artifacts. In addition, local historical material, special collections videos and rare books need to be "sorted" for importance, need, and ownership. Participants stressed the need to sort out copyright issues before any digitalization could occur, which led to a greater concern for time allocations to the possible project.

An additional key factor surfaced through many of the participants' responses regarding the University's need to become a leading body in knowledge management for the local community. Artifacts and local history treasures are being lost to deterioration and neglect; such examples include the California Post Office Mural, and threedimensional artifacts and videos in the special collections. A majority of the participants also stress the need for a unified state run university digital knowledge warehouse that interconnects providing a single-cyber-searchable platform.

This paper suggests further research into other university's archiving and knowledge storage warehousing systems to generate a plan for the state system. Understanding constraints, and following the footwork of Oya Y. Rieger, Preservation in the Age of Large-Scale Digitization [31] paper, which suggests a model for determining small scale library inititives. In contrast to the United States current initivtives, which lack in a national scale and are in the 
infancy, this paper suggests a model for scholars in universities and colleges across the country to initate. The framework of defining small scale kowledge archives and inititives could create a larger body of work, and recoginize a need for a universal data mart of archivable information. The framework of this paper suggests a need for generating a large scale universal model based on it's findings for small colleges and universities to use in determining what knowledge or analog information is needed to be sotred digitally, and what material is most important to scholars and the general public.

The paper also suggests an immediate localized study on what documents should be archived first to protect them from deterioration and destruction, based on the needs of the public and students. It also suggests a comparative study to determine if this need is being capitalized by the other state schools and competing universities in the private sector. Further research should be considered on whether or not a unified digital knowledge warehouse, which contains a knowledge archive of all 14-state run universities' faculty and student research, should be created to protect information.

\section{REFERENCES}

1. Carr, N. (2011). The Shallows: What the Internet Is Doing to Our Brains (Reprint.). W. W. Norton \& Company.

2. Prensky, M. (2001). Digital Natives, Digital Immigrants. On the Horizon (MCB University Press), 9(5), 16.

3. Turkle, S. (1997). Life on the Screen: Identity in the Age of the Internet (First Edition.). Simon \& Schuster.

4. Christensen, C. M., \& Eyring, H. J. (2011). The Innovative University: Changing the DNA of Higher Education from the Inside Out (1st ed.). Jossey-Bass.

5. Seadle, M. (2004). Selection for digital preservation. Library Hi Tech, 22(2), 119-121.The Library of Congress. (2014). Case Study: Born-Digital Community and Hyperlocal news. Retrieved February 2, 2014, from http://www.digitalpreservation.gov/ndsa/

6. Debons, A. (2008). Information Science 101. Scarecrow Press.

7. O'dell, C., \& Grayson, C. J. (1998). If Only We Knew What We Know: The Transfer of Internal Knowledge and Best Practice (1st ed.). Free Press.

8. Polanyi, M. (1961). II.-Knowing and being. Mind, 70(280), 458.

9. Polanyi, M., \& Sen, A. (2009). The tacit dimension. Chicago; London: University of Chicago Press.

10. Dewey, J. (1958). Experience and nature. New York: Dover Publications.

11. Leistner, F. (2012). Connecting Organizational Silos: Taking Knowledge Flow Management to the Next Level with Social Media (1st ed.). Wiley.

12. Davenport, T. H., \& Prusak. (2000). Working knowledge: how organizations manage what they know. Boston, Mass.: Harvard Business School Press.

13. Carr, N. (2008). The Big Switch: Rewiring the World, from Edison to Google (Edition Unstated.). W. W. Norton \& Company.

14. Arthur, W. B. (2009). The Nature of Technology: What It Is and How It Evolves. Free Press.

15. Corti, L. (2012). Recent developments in archiving social research. International Journal of Social Research Methodology, 15(4), 281-290. doi:10.1080/13645579.2012.688310

16. Drucker, P. (1998). Harvard business review on knowledge management. Boston, MA: Harvard Business School Press.

17. O'Neill Adams, M. (2006). The origins and early years of IASSIST. IASSIST Quarterly, Fall(15), 13.

18. Kallinikos, J., Aaltonen, A., \& Marton, A. (2013). The Ambivalent Ontology of Digital Artifacts. MIS Quarterly, 37(2), 357-370.

19. Anbu, K. J. P., \& Chibambo, M. L. N. (2009). Digital Preservation: Issues and Challenges. Trends in Information Management, 5(1), 42-58.

20. Dougherty, W. C. (2010). Can Digital Resources Truly Be Preserved? The Journal of Academic Librarianship, 36(5), 445-448. doi:10.1016/j.acalib.2010.06.016

21. Goethais, A., Jones, J., Kussmann, C., Murray, K., \& Phillips, M. (2012). Who's Minding the (data) Store?: Results of the NDSA Digital Preservation Staffing Survey. NDSA Digital Preservations. Retrieved from http://www.digitalpreservation.gov/ndsa/documents/NDSA-staff-survey-poster-ipres2012.pdf 
22. National Digital Stewardship Alliance. (2013a). Case Study: Citzen Journalism (p. 3). Retrieved from http://www.digitalpreservation.gov/ndsa/working groups/content.html

23. Almond, R. (2009). Digital Decay [Reference, Theory]: digitisation of our civilization, poetics, glitching, circuit bending and data moshing. URL:http://blog.rafolio.co.uk. Retrieved from http://www.creativeapplications.net/scripts/digital-decay-reference-theory/

24. National Digital Stewardship Alliance. (2013b). Case Study: Newspaper E-Prints. The Library of Congress. Retrieved from http://www.digitalpreservation.gov/ndsa/working_groups/documents/NDSA_CaseStudy_Newspa perEPrints.pdf

25. Carraway, L. N. (2011). On Preserving Knowledge. American Midland Naturalist, 166(1), 1-12.

26. Palaiologk, A., Economides, A., Tjalsma, H., \& Sesink, L. (2012). An activity-based costing model for long-term preservation and dissemination of digital research data: the case of DANS. International Journal on Digital Libraries, 12(4), 195-214. doi:10.1007/s00799-012-0092-1

27. Finquelievich, S., \& Rodríguez, E. (2012). Investing in Future: Digital Information Preservation Proposal of Public Policies for South America. DESIDOC Journal of Library \& Information Technology, 32(4), 313-320.

28. Gaur, R. C. \& Tripathi, M. (2012). Digital Preservation of Electronic Resources. DESIDOC Journal of Library \& Information Technology, 32(4), 293-301.

29. Gracy, K. F., \& Kahn, M. B. (2012). Preservation in the Digital Age. Library Resources \& Technical Services, 56(1), 25-43.

30. Asmussen, K. J., \& Creswell, J. W. (1995). Campus Response to a Student Gunman. The Journal of Higher Education, 66(5), 575-591. doi:10.2307/2943937

31. Oya Y. Rieger, Preservation in the Age of Large-Scale Digitization (Washington, D.C.: Council on Library and Information Resources, 2008), (accessed June 28, 2011), cited in Conway, "Preservation in the Age of Google," 68. 